\title{
COMENTARIOS DE JURISPRUDENCIA
}

\section{Las penas de inhabilitación y la condición de funcionario público}

\author{
Pedro Luis Serrera Contreras
}

Abogado del Estado

\begin{abstract}
SUMARIO: I. REFERENCIA A UNA PROPUESTA. POSTURA JURISPRUDENCIAL. II. LA INHABILITACIÓN EN LA LEGISLACIÓN PENAL. III. ALGUNA PRECISIÓN SOBRE LA INHABILITACIÓN. IV. LA LEGISLACIÓN DE FUNCIONARIOS PÚBLICOS. V. LOS PALABRAS CARGO Y EMPLEO. VI. EFECTO ADMINISTRATIVO DE LA INHABILITACIÓN ABSOLUTA. VII. EL PROBLEMA EN LA INHABILITACIÓN ESPECIAL. VIII. PROPUESTA CONCLUSIVA.
\end{abstract}

\section{REFERENCIA A UNA PROPUESTA, POSTURA JURISPRUDENCIAL}

En el número 98 de la Revista de Administración Pública, correspondiente al año 1982, aparece un trabajo de Francisco Javier Montero y Casado de Amezúa, sobre las inhabilitaciones para la profesión de funcionario. Aunque alude a la sanción administrativa de separación del servicio, el grueso de su aportación recae en aquellas inhabilitaciones impuestas por sentencia penal.

Hay que remitirse íntegramente a ese importante trabajo donde se comenta la legislación entonces vigente y se hace un repaso de la doctrina oportuna sobre aquellas materias. Basta ahora con recoger su principal conclusión: «la imposición de la pena de inhabilitación absoluta a funcionarios públicos no debe entrañar de suyo y por la fuerza de los preceptos del Código Penal el que tenga que perderse la condición de funcionario profesional, debiendo considerarse cumplida la pena... con la pérdida del cargo y con la imposibilidad de ostentar ése o cualquier otro durante el tiempo de la condena.» De la lógica de lo expuesto se deduce que esta limitación quedará sin efecto una vez cumplida la condena, sin que sea dable extenderla hasta el momento en que se haya producido además la cancelación de los antecedentes penales. 
Frente a tales propuestas avanzadas que planteaba Montero y Casado, la jurisprudencia de nuestro T.S. no ha abierto puertas a la dulcificación. Cuando se imponía a un funcionario la pena de inhabilitación absoluta o la especial, la consecuencia administrativa había de ser la pérdida de la condición de funcionario. Se venía a decir en reiteradas sentencias, así la de 2 de IV de 2004, que esa condena operaba a modo de condición resolutoria, en virtud de la cual se extinguía la relación funcionarial de aquella persona. Y ciertamente que el tenor de la legislación de funcionarios que después veremos permitía apoyar tal conclusión.

\section{LA INHABILITACIÓN EN LA LEGISLACIÓN PENAL}

Como en la materia que vamos a considerar la legislación penal es fundamental, conviene recordar el añejo código de 30 VIII de 1870. Configuraba como penas la inhabilitación absoluta y la especial, y ambas podían ser o perpetuas o temporales. El artículo 29 prescribía que las de carácter temporal tendrían una duración de 6 años y un día a 12 años.

La pena de inhabilitación absoluta perpetua tenía, conforme al artículo 32, los siguientes efectos:

1. Privación de todos los honores y de los cargos y empleos públicos que tuviere el penado, aunque fueren de elección popular.

2. La privación del derecho de elegir y ser elegido para cargos públicos de elección popular.

3. La incapacidad para obtener los honores, cargos, empleos y derechos mencionados.

4. La pérdida de todo derecho a jubilación, cesantía u otra pensión por los empleos que hubiera servido con anterioridad, sin perjuicio de la alimenticia que el Gobierno podrá concederle por servicios eminentes.

No se comprenden en esta disposición los derechos ya adquiridos al tiempo de la condena por la viuda e hijos del penado.

En el caso de inhabilitación absoluta temporal se repiten los efectos 1, 2 y 3 del artículo 32 , pero en los números 2 y 3 ello se entiende durante el tiempo de la condena.

Conforme al artículo 34, la inhabilitación especial perpetua para cargos públicos producirá los efectos siguientes: 
1. La privación del cargo o empleo sobre que recayere y de los honores anejos a él.

2. La incapacidad de obtener otros análogos.

Cuando la inhabilitación especial es temporal el efecto $1^{\circ}$ es el mismo y el $2^{\underline{o}}$ se limita al tiempo de la condena.

En el Código Penal de 1944 sólo existen las inhabilitaciones temporales, cuya duración es de 6 años y un día a 12 años. Sus efectos vienen establecidos en los artículos 35 y 36 y coinciden con los que el código de 1870 prescribía para las inhabilitaciones de carácter temporal. Esa normativa se reproduce en el Código Penal, texto revisado, de 1963.

En cambio, en el Código Penal aprobado por ley orgánica 10/1995, de 23 XI, hay importantes novedades.

El artículo 39 enumera como penas privativas de derechos: a) la inhabilitación absoluta, b) las de inhabilitación especial para empleo o cargo público, profesión, oficio, industria o comercio, u otras actividades determinadas en este código, o de los derechos de patria potestad, tutela, guarda o curatela, derecho de sufragio pasivo o de cualquier otro derecho; c) la suspensión de empleo o cargo público.

El artículo 40 establece la duración: la pena de inhabilitación absoluta tendrá una duración de 6 a 20 años, las de inhabilitación especial de 3 meses a 20 años, la de suspensión de empleo o cargo público de 3 meses a 6 años.

En otro momento (art. 33) se establece que la pena de inhabilitación especial será grave cuando exceda de 5 años y menos grave en el caso contrario. La absoluta es siempre grave. En cuanto a los efectos de ambas, también hay alguna modificación en el precepto correspondiente.

Artículo 41. «La pena de inhabilitación absoluta produce la privación definitiva de todos los honores, empleos y cargos públicos que tenga el penado, aunque sean electivos. Produce, además, la incapacidad para obtener los mismos o cualquiera otros honores, cargos o empleos públicos, y la de ser elegido para cargos públicos, durante el tiempo de la condena».

Artículo 42. «La pena de inhabilitación especial para empleo o cargo público produce la privación definitiva del empleo o cargo sobre el que recayera aunque sea electivo, y de los honores que le sean anejos. Produce, además, 
la incapacidad para obtener el mismo u otros análogos, durante el tiempo de la condena. En la condena habrán de especificarse los empleos, cargos y honores sobre los que recae la inhabilitación.»

\section{ALGUNA PRECISIÓN SOBRE LA INHABILITACIÓN}

Con referencia a la inhabilitación absoluta, ya Rodríguez Devesa había mantenido, en 1979, en la parte general de su derecho penal, $7^{a}$ edición, que la privación de cargos no lo era durante el tiempo de la condena, como la incapacidad para obtenerlos, sino de forma definitiva. El texto de 1995 le ha dado plenamente la razón, pues habla en efecto de privación definitiva. Incluso para la inhabilitación especial se emplea la misma expresión.

Por lo que se refiere a la inhabilitación especial, es importante el recordatorio de que la sentencia debe especificar el cargo sobre el que recaiga aquella pena... Esto en realidad era consustancial con tal penalidad.

Y así en la S. de 31 X 1975 (RA 4081) el TS mantiene que al no hacerse tal especificación, difícilmente se podría ejecutar la sentencia, al no estar determinado el cargo para el que se inhabilita. Y en aquel caso concreto, tras casar la sentencia de instancia, como se trataba de un supuesto de escándalo público, establece el TS que la privación o incapacidad de cargos sería para aquellos que confieran autoridad sobre menores o impongan a éstos subordinación respecto al penado. Esa doctrina estaba recogida en las sentencias de 9 de Enero 1942, 25 XI 1957 y 23 de Enero 1958.

\section{LA LEGISLACIÓN DE FUNCIONARIOS PÚBLICOS}

Como la condena penal tiene repercusiones administrativas, cual estudiaba Montero y Casado en 1982, conviene examinar lo al efecto establecido en la legislación de funcionarios. Y se comienza con el texto articulado de 7 II 1964.

El artículo 37 establecía:

1. la condición de funcionario se pierde en virtud de alguna de las causas siguientes:

a) Renuncia. 
b) Pérdida de la nacionalidad española.

c) Sanción disciplinaria de separación del servicio.

d) Pena principal o accesoria de inhabilitación absoluta o especial para cago público.

2. La relación funcionarial cesa también en virtud de jubilación forzosa o voluntaria.

El artículo 38 en el apartado 3 añade que la pérdida de la condición de funcionario por separación del servicio tiene carácter definitivo. Esta sanción, conforme al artículo 91, sólo podía imponerse por faltas muy graves. Y entre éstas, el artículo 88 enumeraba la conducta constitutiva de delito doloso.

Pero el precepto verdaderamente extraño de esa ley era el artículo 50, apartado 4, encuadrado en una sección dedicada a la suspensión de funciones: Dice así: 4. «la imposición de la pena de inhabilitación especial para la carrera del funcionario o la absoluta para el ejercicio de funciones públicas, si una u otra fueran con carácter perpetuo, determinará la baja definitiva del funcionario en el servicio, sin otra reserva de derechos que los consolidados a efectos pasivos». Y se habla de extrañeza porque las inhabilitaciones perpetuas hacía tiempo que no estaban en nuestro código penal.

Finalmente, para terminar esta evolución, hay que referirse a la modificación que en el artículo 37 de la ley de funcionarios de 1964 se introdujo por la ley 13/1996 de 30 de XII.

En el apartado 1 la letra d) (relativa a las inhabilitaciones) queda ahora así: d) Pena principal o accesoria de inhabilitación absoluta.

La referencia a la especial pasa a ser un nuevo párrafo dos del apartado 2.: «También se pierde la condición de funcionario cuando recaiga pena principal o accesoria de inhabilitación especial en el ejercicio de las funciones correspondientes al puesto de trabajo o empleo relacionado con esta condición, especificado en la sentencia».

También por esa ley se añaden dos nuevos apartados al artículo 37. El cuarto es el que más interesa: «Los órganos de gobierno de las Administraciones Públicas podrán conceder la rehabilitación, a petición del interesado, de quien hubiera sido condenado a la pena principal o accesoria de inhabilitación, atendiendo a las circunstancias y entidad del delito cometido». 


\section{LAS PALABRAS CARGO Y EMPLEO}

Para delimitar mejor el alcance de la inhabilitación especial, conviene detenerse en las palabras que para la sanción correspondiente emplea el código penal: Habla éste de privación de honores, cargos y empleos públicos. No ofrece dificultad la primera expresión, y sí en cambio el distinguir entre las dos últimas. Sobre ello se pronunciaba Montero y Casado en el trabajo citado al comienzo de estas páginas.

Creemos que se puede hallar el matiz diferencial. En diccionario etimológico de final del XIX cuando se traía la voz cargo se la hacía significar como empleo, puesto, pero especialmente cuando está revestido de cierta dignidad. En tal sentido podríamos decir que tal persona ha ocupado el cargo de ministro o de director general o de gobernador civil o delegado de Hacienda. Lo mismo para el alcalde o presidente de la Diputación. Cargo es pues el puesto que se ocupa en un momento, con independencia de la cualidad administrativa de pertenencia a un determinado cuerpo en que el interesado se integra.

En cambio, empleo alude más bien a la ocupación profesional. De los que trabajan para el sector privado es lógica la expresión de empleados. Y por ello a quienes se ocupan para la Administración se les designa como empleados públicos. La denominación funcionario es algo más moderna. De ahí que en el repertorio legislativo de Aranzadi inicialmente la voz de entrada era la de empleados públicos.

Y ese empleado público lo es por haber ingresado como formando parte de un Cuerpo, bien sean los generales de la Administración Civil o los especiales que existen en ella.

Por lo tanto, una cosa puede ser la privación del cargo de director general o de delegado de Hacienda y otra distinta el empleo público de funcionario perteneciente al Cuerpo Técnico o a algún otro de los especiales.

Incluso dentro de la función pública si hay que buscar los cargos análogos al objeto de la sentencia de inhabilitación, esto puede conseguirse con distintos criterios: Así cabría fijarse en los que supongan un determinado nivel jerárquico (director o subdirector general), los que impliquen autoridad, los que supongan manejo de fondos o numerario, o los que lleven contacto con el público. Con tales criterios podrá precisarse el alcance de la sentencia, cual previene nuestro código penal y la jurisprudencia del TS. 
También en la carrera judicial podría decirse lo mismo. Una cosa es el cargo concreto que se desempeña, como Presidente de Audiencia o de Sala o de Sección, y otra distinta el empleo judicial que a todos corresponde. Incluso de los artículos 317 y 322 de la ley orgánica del poder judicial puede desprenderse esa distinción. Pues para algún supuesto se prevé que incurrir en él implique la pérdida del cargo o puesto y la de la carrera judicial, como cosas distintas.

\section{EFECTO ADMINISTRATIVO DE LA INHABILITACIÓN ABSO- LUTA}

Supuesto todo lo anterior, hora es ya de esbozar nuestra propuesta sobre los efectos administrativos de la condena a inhabilitación. Y para ello es necesario distinguir entre el caso en que se impone la absoluta y aquel en que se aplica la especial.

Para el caso primero de la condena a inhabilitación absoluta, desde luego no es decisivo el articulo 50 apartado 4 de la ley de funcionarios de 1964, en cuanto que habla de penas de duración perpetua que no existen en nuestro Código.

Pero queda el artículo 37 apartado 1 de esa ley, del que claramente se desprende que la pena de inhabilitación absoluta determina la pérdida de la condición de funcionario. Por ello se equipara a la sanción administrativa de separación del servicio que acarrea la misma consecuencia.

Es más, esa conclusión es si cabe más clara tras la reforma de ese artículo 37 en el año 1996. Para la inhabilitación especial hay otra norma específica. Pero para la absoluta el efecto definitivo en cuanto a la carrera pública no puede ser más nítido.

No en balde estamos ante una pena siempre grave y cuya duración de 6 a 20 años está demostrando esa gravedad del reproche culpabilístico.

No es sólo eso. Basta ver las figuras delictivas del Código penal que con relación a los funcionarios están castigadas con la pena de inhabilitación absoluta, para apreciar que aparecen los supuestos de extraordinaria gravedad. Así es el caso de la prevaricación cuando se produce en sentencia por causa penal y en contra del reo. O cuando ocurre el delito de malversación de caudales públicos en los supuestos más agravados. 
En esos casos, que la condena penal a inhabilitación absoluta lleve consigo la consecuencia administrativa de perder la condición de funcionario no es excesivo. Para tal supuesto puede aceptarse esa jurisprudencia rigorista de nuestro TS. Y decimos esto sintiendo apartarnos de la conclusión más benévola que en 1982 había defendido Montero Casado, pero había razones de peso.

\section{EL PROBLEMA EN LA INHABILITACIÓN ESPECIAL}

Consideración muy distinta nos ofrece la condena penal a inhabilitación especial. Tampoco aquí tendría aplicación el apartado 4 del artículo 50 de la ley de funcionarios de 1964, puesto que, aunque allí se alude a tal clase de inhabilitación, lo es para la perpetua que hoy no existe.

En cambio, la reforma del artículo 37 por ley de 1996 tiene ahora especial relevancia. Porque la inhabilitación especial se ha eliminado del apartado 1, que es el que enumeraba las causas de la pérdida de la condición de funcionario. Ciertamente que aquella inhabilitación se recoge en el apartado 2, donde también figuraba la jubilación; pero se hace en términos bien diversos, transcritos en el apartado IV de este trabajo y que permiten una interpretación más benévola.

Porque en ese precepto se insiste en el cargo concreto sobre el que recayere la sanción de inhabilitación, lo que es distinto de la condición de funcionario. Es más, si las consecuencias letales para esa condición fueran exactamente las mismas en los dos casos de inhabilitación, no se comprende la razón de la reforma de 1996. Si el efecto privativo fuera idéntico, sobraba la reforma. Y hay que entender que cuando el legislador se pronuncia no lo hace para lograr absolutamente nada.

Tratar igual a lo que es igual resulta justo. No lo es por el contrario el dar exactamente el mismo trato a las que son situaciones totalmente distintas. Y así ocurre con las dos inhabilitaciones. Incluso la especial está prevista para supuestos de mera imprudencia y no de dolo. También hay que recordar que en esa ley de 1964 la falta muy grave era la actividad propia de delito doloso, nunca la imprudente.

Con el Código penal vigente, la pena de inhabilitación especial comienza con una duración de 3 meses. Que para condenas de algunos meses la consecuencia sea una pérdida definitiva de toda una carrera de funcionario (que hoy no es la del siglo XIX), resulta de un rigor extremado. Nada tiene que ver ello con la inhabilitación absoluta de que antes tratamos. 
Finalmente, dentro de la duración temporal de la pena de inhabilitación especial, nuestro Código penal vigente conceptúa que aquélla es de las menos graves cuando no rebasa los 5 años. Nada de esto puede ocurrir en la inhabilitación absoluta, cuyo mínimo es de 6 .

El que por una condena de unos meses se imponga la consecuencia administrativa de pérdida definitiva de la condición de funcionario, resulta de un rigor extremo. Máxime hoy en que aquella condición se adquiere con no pocos esfuerzos y preparación.

De otro lado, si todo el derecho penal a la vista de la vigente Constitución española debe estar presidido por la finalidad de reinserción del condenado, no se ve cómo ese intento puede ser compatible con aquella consecuencia tan drástica que antes hemos recusado.

Incluso el efecto administrativo letal aplicado a la inhabilitación especial, entendemos pugna abiertamente con el principio de proporcionalidad que cada vez se abre con más fuerza dentro de nuestro ordenamiento. Y si el mismo debe admitirse plenamente dentro del derecho administrativo, mucho más si cabe en la esfera penal. Así se encargó de ponerlo de manifiesto nuestro Tribunal Constitucional en renombrada sentencia que dejó sin efecto una condena penal por excesivamente rigurosa, aunque era ajustada a aquella cuestionada ley.

\section{PROPUESTA CONCLUSIVA}

Para terminar nuestro trabajo no resta sino formular las conclusiones en que el mismo puede materializarse.

En primer lugar que cuando la condena penal lo haya sido a inhabilitación absoluta, ello llevará consigo la privación de la condición de funcionario del condenado. En tal sentido el artículo 37 apartado 1 de la ley de 1964 no necesitaría modificación.

Cuando la pena impuesta fuera la de inhabilitación especial, con duración superior a 6 años, la consecuencia sería la misma que la indicada en el párrafo anterior. La gravedad de la condena así lo permite, pues esa duración coincide con la de la inhabilitación absoluta.

Cuando la inhabilitación especial se impusiera con una duración que no superara los 3 años (pena menos grave aun antes de la última reforma de 
nuestro Código penal) no se daría la pérdida de la condición de funcionario, sino sólo la del cargo o puesto sobre que recayera la condena.

Finalmente si la pena de inhabilitación especial se impusiera con duración superior a 3 años y sin exceder los 6 , acarrearía la pérdida del puesto o cargo; pero en cuanto a la privación de la condición de funcionario, el Gobierno decidiría a la vista de todas las circunstancias objetivas y personales del caso. Es algo parecido a lo previsto en el artículo 37 apartado 4 de la ley de 1964, modificada en 1996.

Para todo esto habría que retocar el apartado 2 del artículo 37 de dicha ley de 1964, amén de derogar expresamente el extraño apartado 4 del artículo 50 de la misma ley. Así se obraría con más justicia al tratar de forma desigual lo que ciertamente no es igual. Y la gradación que se propone se adecuaría más al principio de proporcionalidad tan vinculado a la justicia. 